\title{
La bruja que existe pero no se ve: la invisibilidad cinematográfica como estrategia generadora de terror, desde "Rebeca" hasta "La bruja de Blair"
}

\section{The witch that exists but can not be seen: the cinematographic invisibility as a terror generating strategy, from "Rebecca" to "Blair Witch"}

TIPO DE TRABAJO: Comunicación para presentación virtual.

\author{
PALABRAS CLAVE
}

Bruja, Terror, Invisibilidad, Estereotipo.

KEY WORDS

Witch, Terror, Invisibility, Stereotype.

RESUMEN

En un contexto audiovisual caracterizado por el exceso y el abuso figurativo, parece que funcionan mejor aquellas películas terroríficas en las que el elemento monstruoso no se muestra físicamente ante los ojos del espectador. La finalidad de este texto es la de constatar que, frente a las representaciones cinematográficas normativas, la no-presentación de la figura de la bruja favorece en la contemporaneidad audiovisual a los objetivos de las películas de terror.

Buscando los posibles motivos que propician la creciente constancia del motivo brujesco femenino -invisible o no- en las producciones de este género, se comprobará si la bruja, asimilada como agente de la otredad, actúa como prototipo fílmico ideal de la mujer potencialmente temible; es decir, si para un sistema esencialmente patriarcal, la bruja deviene en el estereotipo aterrador más ajustado a sus fines. Para ello, se tomará como punto de partida el paradigma de la invisibilidad asociada a lo brujeril, Rebeca de Winter, para reflexionar sobre determinados filmes recientes, como La bruja de Blair (Adam Wingard, 2016). Se realizará un análisis basado en la confrontación, estableciendo analogías entre estas películas sin brujas palpables y aquellas otras en las que las hechiceras se vuelven exagerados y cargadas de clichés: Hansel y Gretel: Cazadores de brujas (Tommy Wirkola, 2013), Expediente Warren: The Conjuring (James Wan, 2013), La noche de la bruja (Alex Merkin, 2017), etc. Se concluirá observando si en los casos de estudio analizados surgen diferencias notables deducidas del modo en que se presenta el monstruo; esto es, si se generan significados distintos en función del grado de visibilidad del elemento brujesco, y si los efectos producidos en el espectador varían.

\section{ABSTRACT}

In an audiovisual context characterized by excessive and figurative abuse, it seems that those terrifying films work best in which the monstrous element is not physically shown before the eyes of the spectator. The purpose of this text is to verify that, in contrast to normative cinematographic representations, the non-presentation of the figure of the witch favors the objectives of horror films in audiovisual contemporaneity.

Seeking the possible reasons for the increasing constancy of the witch -invisible or not- in the productions of this genre, it will be verified if the witch, assimilated as an agent of otherness, acts as an ideal film prototype of the potentially fearsome woman; that is, if for an essentially patriarchal system, the witch becomes the frightening stereotype best suited to his objectives. To do this, the paradigm of invisibility associated with witchcraft, Rebeca de Winter, will be taken as a starting point to reflect on certain recent films, 
such as Blair Witch (Adam Wingard, 2016). An analysis based on confrontation will be made, establishing analogies between these films without palpable witches and those in which the sorceresses become exaggerated and loaded with clichés: Hansel and Gretel: Witch Hunters (Tommy Wirkola, 2013), The Conjuring (James Wan, 2013), House of the Witch (Alex Merkin, 2017), etc. It will conclude by observing if in the analyzed study cases there are notable differences deduced from the way in which the monster appears; that is, if different meanings are generated depending on the degree of visibility of the witch, and if the effects produced in the viewer vary.

\section{INTRODUCCIÓN}

La aparentemente hermética figura de la bruja esconde una polisemia fascinante, conllevando aspectos complejos, sugerentes y, en ocasiones, contradictorios. Una primera aproximación semántica permite acotar este concepto, entendido como una construcción cultural socialmente asentada, en base a cuatro perspectivas de estudio: literaria, antropológica, social y feminista. La bruja literaria se yergue como un personaje ficticio, una entidad construida y alejada del plano de lo real. La bruja antropológica, por su parte, apunta al carácter supersticioso de la creencia, así como a lo histórico. El carácter social del término, además de incluir el cliché de la mujer fatal, asocia lo brujesco con la fealdad y la maldad femenina. A todos estos significados podría añadirse un posible punto de vista feminista, el que descubre en la bruja un símbolo de protesta o revolución ${ }^{1}$.

La vigencia de la figura brujesca femenina en el ámbito audiovisual es indudable, pues en todos los años del siglo XXI se han estrenado películas y series con o sobre brujas. Las carteleras han sido hechizadas, sobre todo, por las brujas protagonistas de obras basadas en procesos históricos famosos, de versiones o reinterpretaciones de relatos tradicionales y de cintas calificadas de terror. El uso de lo brujesco en el terreno fílmico se encuentra intensamente condicionado por la naturaleza económica y mercantil de este, por lo que difiere de lo que ocurre en otros contextos. En la ficción de la gran pantalla, las protagonistas mágicas tienden a reproducir fielmente estándares literarios, y se sitúan en argumentos manidos, vacíos de contenido o cuidadosamente integrados en un sistema de valores patriarcal. Por el contrario, reparando en la bruja como material y temática en las artes visuales, se deduce que esta suele detentar un carácter político afín a la reivindicación feminista ${ }^{2}$.

Las múltiples investigaciones relacionadas con la bruja abordan el concepto desde enfoques heterogéneos, dentro de los que sobresalen los estudios dedicados a lo cinematográfico. En nuestro análisis del estado de la cuestión no hemos encontrado una cantidad significativa de trabajos vinculados concretamente con el género del terror, pero ha sido esencial la lectura de autoras como Pilar Pedraza, María Jesús Zamora Calvo y Erika Bornay.

Este trabajo se centra en el análisis de la imagen contemporánea de la bruja en las creaciones cinematográficas de terror. El objetivo principal será verificar que el personaje brujesco femenino como sujeto aterrador funciona mejor cuando su imagen no aparece, cuando la bruja se caracteriza por la invisibilidad. Se comprobará además que esta bruja invisible presenta diferentes grados de materialidad o definición, y se establecerán confrontaciones entre sus significados y los que se originan cuando la imagen brujesca se vuelve corpórea y, consecuentemente, estereotipada.

Son varias las creaciones terroríficas que se han aproximado al mundo de la brujería, pero se han seleccionado aquellas que suponen una muestra representativa para nuestra hipótesis: El proyecto de la bruja de Blair (1999), Hansel y Gretel: cazadores de brujas (2013), Expediente Warren: The Conjuring (2013), La bruja de Blair (2016), La noche de la bruja (2017).

\section{La otredad, rasgo que define al personaje brujesco femenino}

Antes de tratar las particularidades de los relatos cinematográficos en los que la bruja se asocia con el género del terror, se torna imprescindible realizar un breve acercamiento a los conceptos de miedo, monstruo y cine de terror. El Diccionario de la Real Academia de la Lengua Española (RAE) describe el término terror como el "miedo muy intenso", mientras que el miedo es la "angustia por un riesgo o daño real o imaginario". Dentro de este maravilloso campo semántico, la definición más estimulante es probablemente la de horror, que apunta simultáneamente a la "monstruosidad" y a la sensación profunda provocada por lo terrible.

El miedo puede proceder de algo verídico o inventado. La bruja antropológica presenta ambas circunstancias: existe en el plano de lo real como curandera -cargada de poderes relacionados con la naturaleza y la herbología-, pero provoca un sentimiento de recelo

\footnotetext{
${ }^{1}$ En torno a la percepción feminista de la brujería, conviene citar los siguientes proyectos teóricos: VV.AA. (2015). W.I.T.C.H (Conspiración terrorista Internacional de las Mujeres del Infierno), COMUNICADOS Y HECHIZOS, Madrid, La Felguera; FEDERICI, Silvia (2010). Calibán y la bruja: mujeres, cuerpo y acumulación originaria, Madrid, Traficantes de sueños.

${ }^{2}$ Véanse obras como Tremble, tremble de Jesse Jones o The Book of Evil Spirits de Chiara Fumai.
} 
entre sus vecinos que, en sus derivas imaginadas, la asocian con lo diabólico y lo perverso. Sin embargo, son las perspectivas social y feminista las que nos ofrecen una lectura más interesante del miedo a lo brujesco femenino. Cuando se suceden las persecuciones inquisitoriales o cuando en el siglo XIX surge el estereotipo artístico de la femme fatale ${ }^{3}$, los perseguidores y los creadores manifiestan un miedo agudo a la mujer independiente.

Observando los matices de cada una de las palabras presentadas anteriormente y, abordando sobre todo el horror, resulta inevitable mencionar los trabajos teóricos de Julia Kristeva y Pedro Azara. Agregando la idea de borde, Kristeva (2006: 11) afirma que lo abyecto es "aquello que perturba una identidad, un sistema, un orden; aquello que no respeta los límites, los lugares, las reglas". La bruja, como entidad ajena a todo lo estructurado -sociedad, familia, canon, etc.-, como gran disidente, parece el ejemplo idóneo para la abyección. En cuanto a lo terrorífico en el medio cinematográfico, la asiduidad del motivo brujesco femenino en los filmes de este género tal vez se debe al hecho de que el horror subraya lo diferente, lo ajeno (Pinel 2009: 169), y la bruja puede ser entendida como ese otro monstruoso y temible. Es decir, la asociación de la mujer con la otredad es lo que hace que la bruja se convierta en el estereotipo terrorífico ideal según las normas del patriarcado.

Respecto a los rasgos formales y según la investigadora Giulia Colaizzi (1995: 81), el monstruo cinematográfico femenino se define por la abyección. Aunque la RAE explica la abyección como "envilecimiento extremo" -definición que no deja de tener interés para nuestro estudio-, se vuelve más adecuada la ya mencionada teoría de Kristeva. Los personajes monstruosos femeninos -las brujas en nuestro caso- no son atroces únicamente por su aspecto, sino por su ambigüedad, por su corrupción y por el desvío maligno de la norma (Kristeva 2006: 25). Siguiendo estos rasgos, parece que lo brujesco en el ámbito audiovisual adquiere un carácter espectacular a través de una suerte de estrategia de pulimento formal. El monstruo se apropia en la contemporaneidad visual de una belleza extraña, se vuelve consumible y "satinado" (Han 2015: 19). La bruja, igual que ciertas obras artísticas caracterizadas por la fealdad, se vuelve repulsiva por lo que implica, no por la forma en que se la muestra en la creación (Azara 1990: 24).

Por otra parte, se percibe en el asunto de lo terrorífico una transformación similar a la existente entre la bruja contracultural y la protagonista de ficciones audiovisuales. El miedo, cuestión intrínseca al fenómeno de la brujería histórica, pasa de ser un mecanismo de control empleado por los perseguidores a funcionar como un reclamo argumental para un público concreto. La bruja es, en este sentido, un personaje fílmico que aterra y entretiene a partes iguales. Lo terrorífico se convierte en diversión de igual modo que el castigo deviene en espectáculo en los llamados Autos de Fe. En estos procesos inquisitoriales públicos existe una teatralidad buscada, así como un afán por impresionar, aleccionar al pueblo (Romano, 2007, 152) y demostrar poder. El miedo se transforma en este contexto en el método más adecuado para lograr determinados fines políticos basados en la opresión. Anna Adell entiende el castigo público como un ritual que señala a las víctimas y demuestra el poder soberano (Adell 2011: 9). El fenómeno teatral del Auto de Fe encuentra representación cinematográfica en una escena de la película Me casé con una bruja (René Clair, 1942), donde los asistentes a una ejecución colectiva por brujería deciden comer palomitas: es la muerte concebida como espectáculo fílmico.

\section{La bruja en el ámbito cinematográfico del terror}

Aunque se abordan principalmente obras estrenadas a partir del año 2000, conviene subrayar uno de los paradigmas de la invisibilidad brujesca audiovisual y literaria: el personaje de Rebeca. La mujer que da nombre al conocido filme dirigido por Alfred Hitchcock en 1941 no aparece en ningún momento del metraje y, sin embargo, es capaz de atemorizar cruelmente a la joven esposa de Max de Winter ${ }^{4}$. Podría entenderse que el poder de esa Rebeca invisible se materializa en su perversa ama de llaves, la señora Danvers, pero lo cierto es que el miedo que siente el personaje interpretado por Joan Fontaine es principalmente producido por el fantasma de Rebeca y por sus recuerdos.

Tras la no-imagen de la aterradora Rebeca, el caso más recordado es el de Elly Kedward ${ }^{5}$. La primera película relacionada con esta hechicera es El proyecto de la bruja de Blair (Daniel Myrick y Eduardo Sánchez, 1999), un producto que nace paralelamente a una gran campaña de marketing publicitario: los espectadores podían visitar una página web con material diverso, visualizar un documental emitido en televisión o toparse con carteles ilustrados con fotografías de los jóvenes supuestamente desaparecidos. El contexto extracinematográfico de la obra determina el punto de vista del receptor, esto es, condiciona su lectura de la creación. De este modo, la historia es comprendida como real, lo que significa que el público asimila que la bruja de Blair existe. Son los títulos de crédito finales los que, a pesar de la espontaneidad que define diálogos y actores, señalan lo ficticio del argumento. Se trata de una cinta de ficción con aspecto documental cuya secuela, La bruja de Blair (Adam Wingard, 2016), se ha estrenado recientemente, presentando una factura formal y conceptual similar a la primera.

\footnotetext{
${ }^{3}$ Véanse BORNAY, Erika (2001). Las hijas de Lilith, Madrid, Ediciones Cátedra, Anaya; DIJKSTRA, Bram (1994). Ídolos de la perversidad. La imagen de la mujer en la cultura de fin de siglo, Barcelona, Debate.

${ }^{4}$ Curiosamente, el personaje de la nueva señora de Winter -a diferencia de la primera, que da título al libro de Daphne du Maurier y a su versión cinematográfica- no tiene nombre.
}

${ }^{5}$ Elly Kedward es un anagrama de Edward Kelley, famoso ocultista inglés del siglo XVII (García 2014). 
Atendiendo ya al personaje brujesco, se vuelve importante indicar que en la primera película, Elly Kedward, como Rebeca, no se persona en pantalla en ningún momento de la cinta. Sin embargo, el miedo que percibe el receptor es indudable, tal vez incrementado por la ya comentada carga extra-cinematográfica. La amenaza se manifiesta en el método de grabación y en la angustia de los personajes, así como en determinadas claves que nutren la leyenda de Ekward: montones de piedras, formas satánicas construidas con ramas, etc. La única diferencia entre la cinta de 1999 y la de 2016 que puede resultar interesante para nuestra investigación es el hecho de que en la última sí se ve a la bruja, representada como una silueta desdibujada, oscura y alargada -fig. 1-. La extraña morfología de Elly Kedward encuentra un cierto sentido en el guion de Simon Barrett, pues uno de los personajes detalla la muerte de la hechicera: colgada con piedras en las piernas para estirarla, "como un potro improvisado".

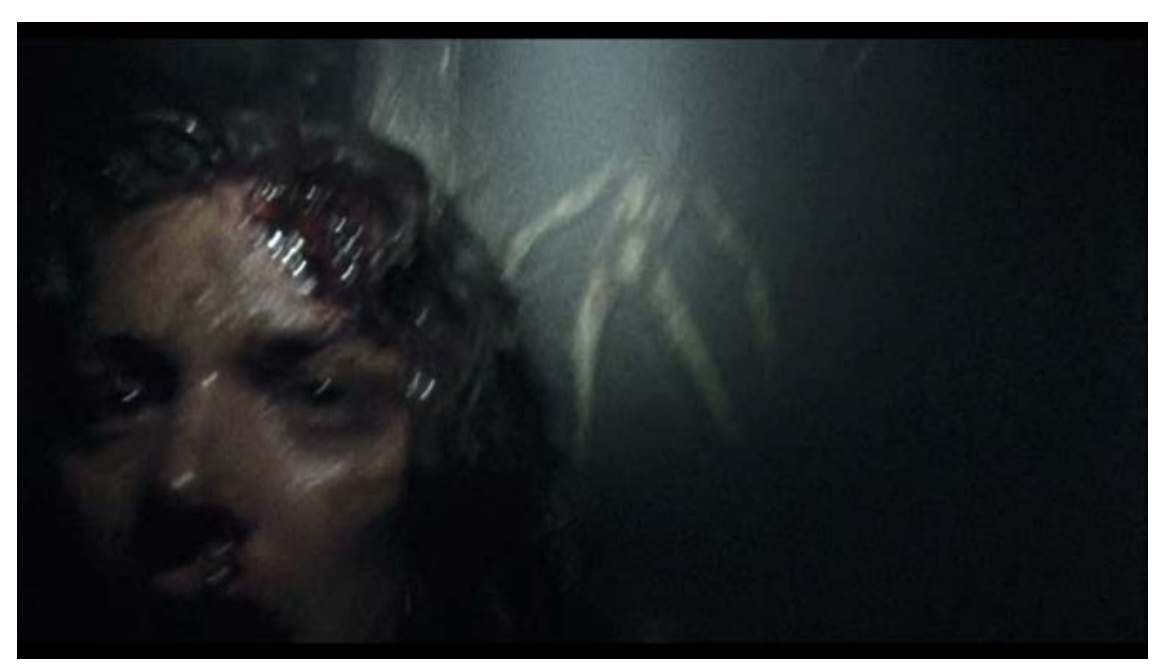

Figura 1. Escena de La bruja de Blair (Adam Wingard, 2016).

En el lado opuesto a esta incorporeidad brujesca emergen ejemplos visuales significativos, entre los que destaca la perversa hechicera creada por James Wan en Expediente Warren: The Conjuring (2013). Lorraine Warren explica que Bathsheba, esta maga malévola, es pariente de Mary Towne Eastey, una de las mujeres asesinadas por brujería en el Salem del siglo XVII. Estéticamente, las apariciones físicas del personaje brujesco son normativas y seguidoras de los clásicos estereotipos literarios. Ataviada únicamente con un camisón de color claro y con el pelo enredado y sucio, su rostro es el de una anciana con signos de putrefacción y violencia. En el plano que muestra cómo Lorraine la ve colgada de la rama de un árbol solo se advierten sus pies, descalzos y notablemente sucios. Como es sabido, el arquetipo de la mujer descuidada, greñuda y vestida con una tela blanca es frecuente en este tipo de películas, y así se dibuja también a la vengativa Annabel Foster ${ }^{6}$ en La noche de la bruja (2017), bajo una maraña de harapos y sábanas de color blanco.

La marcada ancianidad de estas dos hechiceras, deudora de los estereotipos creados por Perrault, Andersen y los hermanos Grimm ${ }^{7}$, nos permite hallar una correspondencia visual clara entre el cuerpo brujesco y el de la vieja. Ambos se entienden como algo horroroso (Pedraza 2012: 6) y lo horroroso, lo que provoca miedo, enlaza con la etimología inglesa de la palabra ugly: "ser temido" (Henderson 2018: 9).

La suciedad inherente a Bathsheba y Annabel Foster domina los rostros de las perversas brujas de Hansel y Gretel: cazadores de brujas (Tommy Wirkola, 2013), película cuya trama no es en esencia terrorífica pero que, probablemente, lograría resultados más aterradores con una construcción distinta de los personajes brujescos femeninos. El propio Hansel explica el terrible aspecto de las hechiceras afirmando que las brujas crueles no pueden disimular, la podredumbre se apodera de sus cuerpos: son mujeres de piel seca y agrietada, ojos amarillentos, grandes arrugas y ojeras, cabellos oscuros o canosos y dientes ennegrecidos -fig. 2-.

\footnotetext{
${ }^{6}$ Posible alusión a Ann Foster, acusada y encarcelada en los denominados Juicios de Salem.

${ }^{7}$ Véanse las descripciones de brujas como la de Hansel y Gretel o la de La bella durmiente, respectivamente: "entonces se abrió de repente la puerta y salió arrastrándose pesadamente una anciana decrépita, que caminaba apoyándose en un bastón" (Grimm 1979: 23); “[era un] hada vieja, con la cabeza sacudida por un temblor que más se debía al despecho que a la vejez" (Bettelheim 1980: 40).
} 

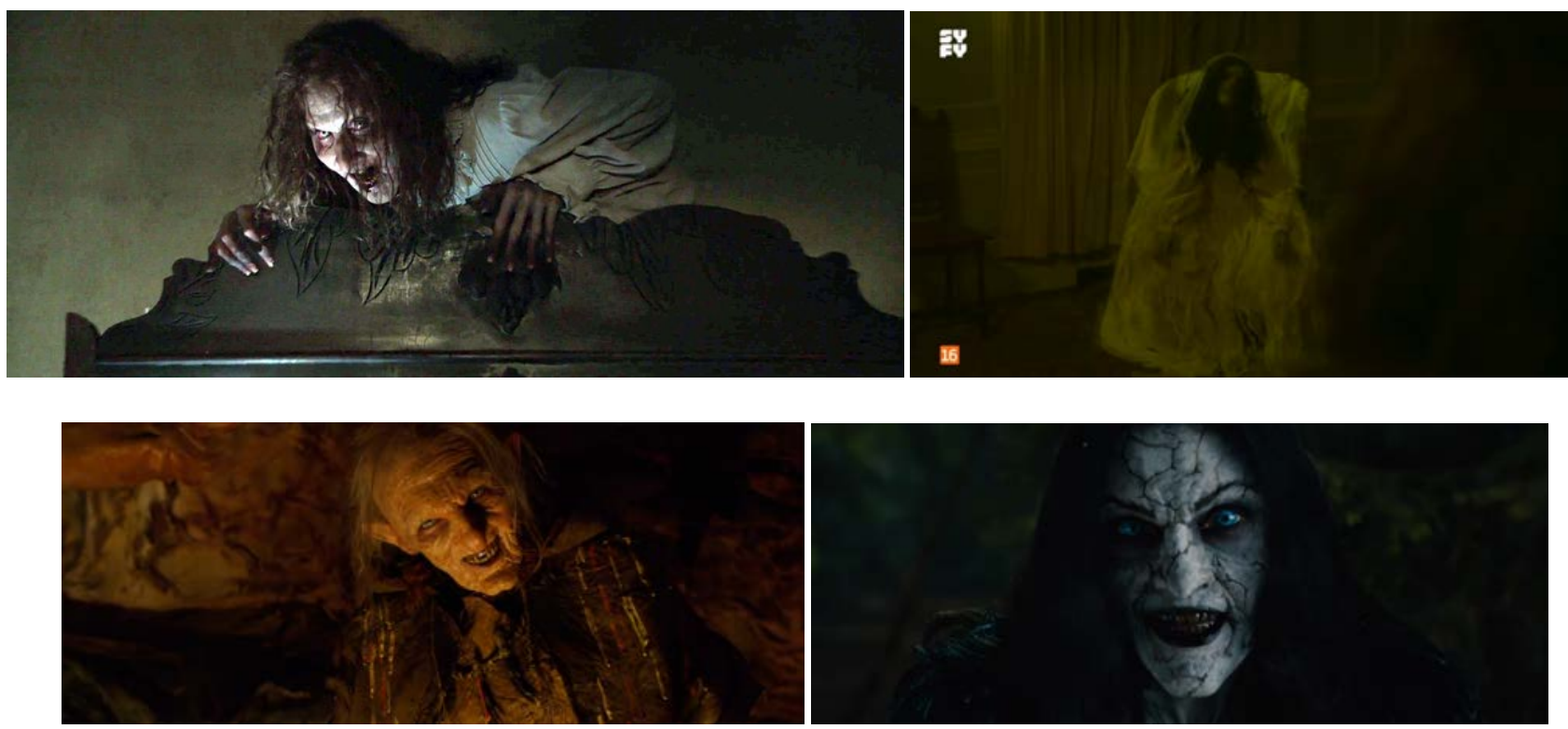

Figura 2. Imágenes de Bathsheba, Annabel Foster y dos de las brujas de Hansel y Gretel: cazadores de brujas (Tommy Wirkola, 2013).

Entre la total invisibilidad y la representación literal del estereotipo brujesco surgen soluciones intermedias. Ya se ha visto que la última obra sobre la bruja de Blair muestra a Elly Kedward durante unos segundos, pero lo hace como una silueta casi amorfa, estirada y entre sombras. Asimismo, podríamos referirnos en este punto a los retratos brujeriles ofrecidos en en La autopsia de Jane Doe (André $\varnothing$ vredal, 2016) y La bruja (Robert Eggers, 2016). La peculiaridad de estas creaciones radica en que, a pesar de que la presencia en pantalla del elemento brujesco femenino es constante, el peso del cliché es considerablemente menor. Ambas cintas presentan a la hechicera principal en el cuerpo de una mujer joven y acorde a la belleza normativa.

Aunque en la escena del aquelarre final -fig. 3- destacan las mujeres jóvenes, cabe añadir que la película de Robert Eggers cuenta también con el modelo de la vieja infame. De hecho, una de las escenas más evocadoras es la que protagoniza esta anciana hábilmente disfrazada de una joven muchacha -fig. 4-. Remitiendo a idea de la mujer fatal y a la máscara empleada por la perversa madrastra de Blancanieves, la bruja del bosque seduce a uno de los niños de la familia protagonista y, cuando lo tiene bajo su poder sexual, desvela su verdadera apariencia.
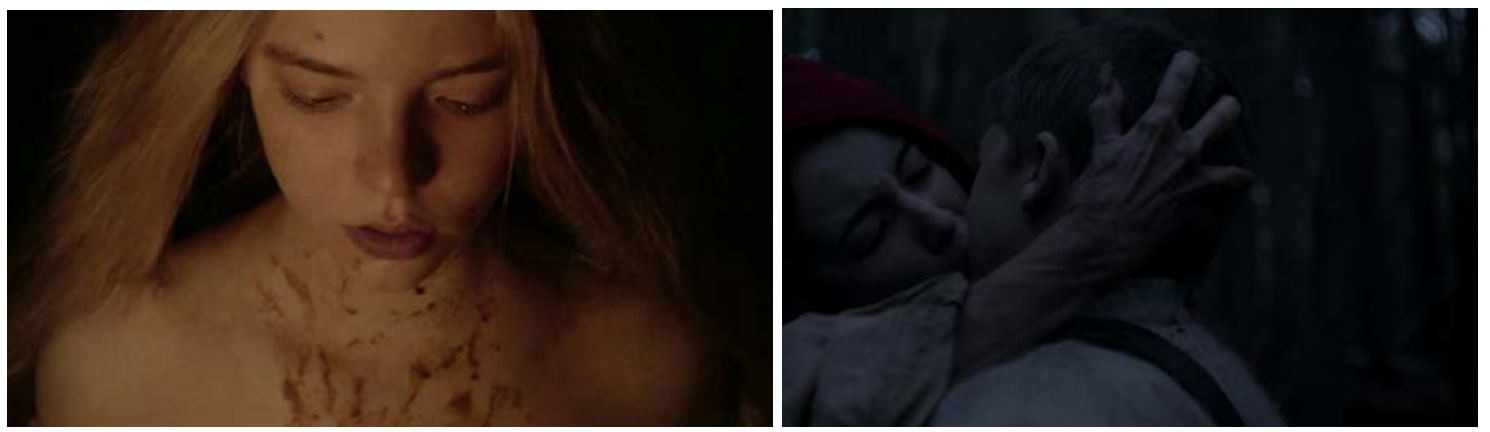

Figuras 3 y 4. Escenas de La bruja (Robert Eggers, 2016).

Aprovechando la mención a la madrastra, corresponde subrayar la capacidad de esta figura, equiparada con la de la bruja, para encarnar un peligro primigenio y esencial, un peligro que se encuentra "en nuestro propio hogar, generalmente en las figuras femeninas que nos rodean" (Torres Begines 2015: 44). Precisamente a todo lo incluido dentro del hogar -y abarcando con amplitud este término- se refiere la expresión "lo familiar extraño", que engloba los objetos y sujetos cotidianos que "nos dan sobresaltos" (De Diego 1999: 13). 


\section{CONCLUSIONES}

Observando el breve recorrido trazado en torno al cine de terror y al modo en que este utiliza la poliédrica figura de la bruja, se puede confirmar que existen diferentes grados de visibilidad del elemento brujesco femenino. Esta situación es evidente en la confrontación entre la bruja transparente protagonista del filme El proyecto de la bruja de Blair y la de la putrefacta anciana de Expediente Warren: The Conjuring. Los casos de estudio revisados demuestran que, en general, cuanto menos explícita es la imagen brujeril, más carga terrorífica implica.

En definitiva, la invisibilidad de la imagen brujesca favorece el terror fílmico por diversos motivos. Primero, porque evita representaciones estereotipadas, manidas y sexistas, que son, a su vez, repeticiones visuales para un receptor mínimamente especializado. Segundo, porque la exagerada caracterización de la bruja provoca en el espectador un alejamiento de la trama y del ambiente cinematográfico, impide el efecto catártico y supone una ruptura del sentimiento terrorífico. $Y$ tercero, porque el hecho de que el agente peligroso sea imperceptible a la mirada permite que el público complete o construya su propia imagen.

Este último fundamento nos parece el primordial, pues enlaza con la idea de lo abyecto y de la otredad, de lo que Estrella de Diego definía como "lo familiar extraño". Si gracias a la invisibilidad es el espectador el que termina de construir la monstrua brujesca, la llevará a su terreno y será capaz de infundirle su temor más profundo.

\section{FUENTES REFERENCIALES}

Adell, A. (2011). El arte como expiación. Madrid: Casimiro libros.

Bettelheim, B. (1980). Los cuentos de Perrault. Barcelona: Editorial Crítica.

Colaizzi, G. (ed.) (1995). Feminismo y teoría fílmica. Valencia: Ediciones Episteme.

De Diego, E. (1999). Procesiones íntimas. En Annette Messagger. La procesión va por dentro (1999). Madrid, Museo Nacional Centro de Arte Reina Sofía (catálogo de la exposición celebrada en Madrid del 9 de febrero al 3 de mayo de 1999).

García, Y. (2014, 1 de noviembre). 20 cosas que (probablemente) no sabías de 'El proyecto de la bruja de Blair'. Elmundo.es. Recuperado de http://cinemania.elmundo.es/noticias/20-cosas-que-probablemente-sabias-de-el-proyecto-de-la-bruja-de-blair/

Grimm, J., y Grimm, W. (1979). Cuentos. Madrid: Alianza Editorial.

Han, B.-C. (2015). La salvación de lo bello. Barcelona: Herder.

Henderson, G. E. (2018). Fealdad: una historia cultural. Madrid: Turner.

Kristeva, J. (2006). Poderes de la perversión. Ensayo sobre Louis-Ferdinand Céline. México D.F.: Siglo XXI Editores.

Pedraza, P. (2012). La vieja desnuda. Brujería y abyección. Recuperado de https://cvc.cervantes.es/literatura/aispi/pdf/13/13 011.pdf

Pinel, V. (2009). Los géneros cinematográficos: Géneros, escuelas, movimientos y corrientes en el cine. Barcelona: Ediciones Robinbook.

Romano, V. (2007). Sociogénesis de las brujas. El origen de la discriminación de la mujer. Madrid: Editorial Popular.

Torres Begines, C. (2015). Soy mala porque el mundo me ha hecho así: la evolución de las malvadas brujas-madrastras de Blancanieves y La Bella Durmiente. Espéculo. Revista de Estudios Literarios. UCM, 55, 43-51.

Nota: Las imágenes que acompañan este texto se usan exclusivamente como complemento visual del mismo. Se trata de capturas de pantalla extraídas de las películas mencionadas. Los derechos de autor pertenecen a sus creadores, así como a las empresas productoras: Lionsgate, Vertigo Entertainment, Room 101, Snoot Entertainment, Warner Bros, New Line Cinema, Evergreen Media, The Safran Company, Distilled Media, Syfy, MGM, Studio Babelsberg, Gary Sanchez Productions, Paramount Pictures. 